OPEN ACCESS

Edited by:

Basil J. Nikolau,

lowa State University, USA

Reviewed by:

Masami Yokota Hirai,

RIKEN Center for Sustainable

Resource Science, Japan Rita Maria Zrenner,

Leibniz Institute of Vegetable and Ornamental Crops (LG), Germany

${ }^{*}$ Correspondence:

Wei Ji

iwei_ji@neau.edu.cn

tThese authors have contributed equally to this work.

Specialty section: This article was submitted to Plant Metabolism and Chemodiversity, a section of the journal Frontiers in Plant Science

Received: 29 April 2016 Accepted: 12 August 2016

Published: 29 August 2016

Citation:

Kong W, Li J, Yu Q, Cang W, Xu R, Wang Y and Ji W (2016) Two Novel Flavin-Containing Monooxygenases Involved in Biosynthesis of Aliphatic

Glucosinolates.

Front. Plant Sci. 7:1292. doi: 10.3389/fpls.2016.01292

\section{Two Novel Flavin-Containing Monooxygenases Involved in Biosynthesis of Aliphatic Glucosinolates}

\author{
Wenwen Kong ${ }^{1+}$, Jing $\mathrm{Li}^{1+}$, Qingyue $\mathrm{Yu}^{1}$, Wei Cang ${ }^{1}$, Rui $\mathrm{Xu}^{1}$, Yang Wang ${ }^{2}$ and Wei $\mathrm{Ji}^{1 *}$ \\ ${ }^{1}$ Department of Plant Biotechnology, College of Life Science, Northeast Agricultural University, Harbin, China, ${ }^{2}$ Department \\ of Cell Biology, College of Life Science, Northeast Forestry University, Harbin, China
}

Glucosinolates, a class of secondary metabolites from cruciferous plants, are derived from amino acids and have diverse biological activities, such as in biotic defense, depending on their side chain modification. The first structural modification step in the synthesis of aliphatic (methionine-derived) glucosinolates-S-oxygenation of methylthioalkyl glucosinolates to methylsulfinylalkyl glucosinolates-was found to be catalyzed by five flavin-containing monooxygenases (FMOs), FMOGS-OX1-5. Here, we report two additional $\mathrm{FMO}_{\mathrm{GS}-\mathrm{OX}}$ enzymes, $\mathrm{FMO}_{\mathrm{GS}-\mathrm{OX6} 6}$, and $\mathrm{FMO}_{\mathrm{GS}-\mathrm{OX} 7}$, encoded by At1g12130 and At1g12160, respectively. The overexpression of both $F M O_{G S-O x 6}$ and $F_{M O} O_{G S-O X 7}$ decreased the ratio of methylthioalkyl glucosinolates to the sum of methylthioalkyl and methylsulfinylalkyl glucosinolates, suggesting that the introduction of the two genes converted methylthioalkyl glucosinolates into methylsulfinylalkyl glucosinolates. Analysis of expression pattern revealed that the spatial expression of the two genes is quite similar and partially overlapped with the other $F M O_{G S-O X}$ genes, which are primarily expressed in vascular tissue. We further analyzed the responsive expression pattern of all the seven $F M O_{G S-O X}$ genes to exogenous treatment with abscisic acid, 1-aminocyclopropane-1-carboxylic acid (ACC), jasmonic acid (JA), salicylic acid, indole-3-acetic acid (IAA), and low and high temperatures. Although these genes showed same tendency toward the changing stimulus, the sensitivity of each gene was quite different. The variety in spatial expression among the $F M O_{G S-O X}$ genes while responding to environmental stimulus indicated a complex and finely tuned regulation of glucosinolates modifications. Identification of these two novel $\mathrm{FMO}_{\mathrm{GS}-\mathrm{OX}}$ enzymes will enhance the understanding of glucosinolates modifications and the importance of evolution of these duplicated genes.

\footnotetext{
Keywords: Arabidopsis thaliana, flavin-containing monooxygenase (FMO), glucosinolates, S-oxygenation, expression pattern
}

\section{INTRODUCTION}

Glucosinolates (GSLs) are amino acid-derived natural products primarily present in plants belonging to the Brassicaceae family, such as cabbage, broccoli, and the model plant Arabidopsis thaliana. Upon wounding or mastication, GSLs are hydrolyzed by myrosinases (thioglucosidases) and release hydrolysis products, primarily isothiocyanates and nitriles 
(Halkier and Gershenzon, 2006; Bones and Rossiter, 2006; Zhang et al., 2006). These breakdown products exert diverse biological effects such as induction of direct toxic effects or other defense responses against pathogens and generalist herbivores (Bednarek et al., 2009; Clay et al., 2009; Hopkins et al., 2009; Laluk et al., 2012). In humans, the isothiocyanates derived from some aliphatic (methionine-derived) GSLs are considered to have numerous health benefits including potent anti-cancer property (Fahey et al., 1997, 2002; Rose et al., 2000; Zalcmann and Talalay, 2001). The most well-studied isothiocyanate is sulforaphane, which is derived from 4-methylsulfinylbutyl GSL; it can decrease the risk of various cancers such as breast cancer, prostate cancer, gastric cancer, and skin cancer (Fahey et al., 2002; Rose et al., 2005; Talalay et al., 2007; Atwell et al., 2015; Chang et al., 2015; Fofaria et al., 2015). Aliphatic GSLs are synthesized in three steps-elongation of methionine chain, formation of GSL core structure, and modification of side chain. The diverse biological activities of GSLs are largely dependent on the chemical modifications in their side chain.

The basic aliphatic glucosinolate molecules, methylthioalkyl (MT) GSLs, which contain only the core structure, may undergo a variety of secondary modifications such as oxidation, hydroxylation, or desaturation. The first step in side-chain modification is $S$-oxygenation, which converts MT GSLs to methylsulfinylalkyl (MS) GSLs. Thus, S-oxygenation is of biological as well as biochemical interest because it influences not only the biosynthesis of MS GSLs, but also the further modification and the resulting activity of their hydrolysis products.

Five flavin-containing monooxygenases (FMOs), $\mathrm{FMO}_{\mathrm{GS}-\mathrm{OX1}-5}$, have been identified to catalyze $S$-oxygenation during the conversion of MT GSLs to MS GSLs (Hansen et al., 2007; Li et al., 2008). In phylogenetic analysis of FMOs containing the conserved FMO $_{\mathrm{GS}-\mathrm{OX}}$ domains in Arabidopsis, At1g12130 and Atlg12160 clustered to the same subclade and, together with $\mathrm{FMO}_{\mathrm{GS}-\mathrm{OX1}-5}$, formed a seven-protein group (Figure 1A). In a previous study, a phylogenetic tree of plant-derived FMOs in rice, Arabidopsis, and poplar was analyzed, and this sevenprotein group was involved in the predicted $S$-oxygenation clade and was present only in the GSL-producing Arabidopsis plant. Thus, these genes were predicted to be involved in the $S$-oxygenation of GSL (Figure 1B). Further, another FMOcoding gene, At1g12200, was suggested as a candidate $F M O_{G S-O X}$ due to its strong co-expression with other GSL biosynthetic genes in response to Sclerotinia sclerotiorum (Stotz et al., 2011) infection. Therefore, in our study, we investigated At1g12130, At1g12160, and At1g12200 as $\mathrm{FMO}_{\mathrm{GS}-\mathrm{OX}}$ candidate genes. It

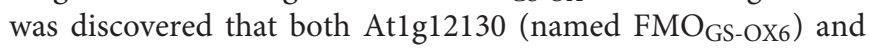
At1g12160 (named FMO $_{\mathrm{GS}-\mathrm{OX} 7}$ ) are involved in S-oxygenation of aliphatic GSLs, while At1g12200 does not possess the expected activity.

To better understand the coordination of these FMO $\mathrm{GS}_{\text {-OX }} \mathrm{S}$ and the upstream aliphatic GSL biosynthetic genes, responsive expression pattern of these genes toward several hormone treatments and environmental conditions are detected. Integrating the knowledge of catalysis, distribution and responsive pattern of these $\mathrm{FMO}_{\mathrm{GS}-\mathrm{OX}}$, we speculate that on one hand, these duplicated genes are redundant and might functionally compensate and increase genetic robustness, whereas on the other hand, they show delicate functional variation and possibly contribute to the complex and finely tuned regulation of GSLs modification.

\section{MATERIALS AND METHODS}

\section{Generation of Phylogenetic Tree}

All the FMO protein sequences with conserved GS-OX domains in Arabidopsis were obtained from NCBI (Marchler-Bauer et al., 2015) and the full-length amino acid sequences of these proteins were aligned using ClustalX with default parameters. A phylogenetic tree was constructed using the neighbor-joining method with Mega software (version 5.0). Bootstrap support for the topology was estimated from 1000 replicates, and nodes occurring in less than $50 \%$ of the replicates were collapsed.

\section{Plant Material and Growth Conditions}

Wild-type (Col-0) and mutants of Arabidopsis seeds were obtained from Arabidopsis Biological Resource Center. Genotype of FMOGS-OX6 T-DNA insertion mutant (SALK_209008) was analyzed by PCR using the following three primers, 5'-CCGCCTAATTCAATCAGCTC-3', 5'-GAGGC TCAGTGAGATGACC-3', and the T-DNA-specific primer LBa1 5'-TGGTTCACGTAGTGGGCCATCG-3'. Genotype of FMO $_{G S-O X 7}$ T-DNA insertion mutant (SALK_062129) was analyzed by PCR using the following three primers, $5^{\prime}$-AAAC CGTGAAGATTGCAATTG-3', 5'-GACGAGGCTCAGTGAAG TGAC-3', and the T-DNA-specific primer LBal 5'-TGGTT CACGTAGTGGGCCATCG-3'. Genotype of At1g12200 T-DNA insertion mutant (SALK_136282) was analyzed by PCR using the following three primers, 5'-CCGCCTAATTCAATCAGCTC-3', $5^{\prime}$-GAGGCTCAGTGAAGTGACC-3', and the T-DNA-specific primer LBa1 5' -TGGTTCACGTAGTGGGCCATCG-3'.

Plants were grown in a growth chamber with $16 \mathrm{~h}$ light $/ 8 \mathrm{~h}$ dark photoperiod at a photosynthetic photon flux density of $100 \mu \mathrm{molm}^{-2} \mathrm{~s}^{-1}$ at 20 and $70 \%$ relative humidity, respectively.

\section{Plasmid Construction and Plant Transformation}

To prepare the overexpression constructs $35 S:: F M O_{G S-O X 6}$, 35S::FMO $\mathrm{GS}_{\text {-OX7 }}$, and 35S::At1g12200, coding sequences (CDS) of $F_{M M O} O_{G-O X 6}, F_{M O S}$-OX7 and At1g12200 were amplified through reverse transcription-PCR (RT-PCR) method. The total RNA from plant was isolated with TRIzol reagent according to the manufacturer's instructions. First-strand cDNA was synthesized using the SupermoIII RT kit (Bioteke). The CDS of $\mathrm{FMO}_{G S-O X 6}, \mathrm{FMO}_{G S-O X 7}$ and At1g12200 were amplified with Pfu Turbo Cx Hotstart DNA polymerase (Stratagene) from the first-strand products using the following primers, respectively: 5'-GGCTTAAUATGACACCACCGCCTAATTC-3', 5'-GGTTTAAUTTATGTAGACCAAACTTTGCTCG-3' and 5'-GGCTTAAUATGACCAGCGTAATCACCTC-3', 5'-GGTTT AAUCTAAGAAGAACAATCTTGGTTCG-3', and $5^{\prime}$-ATGG 


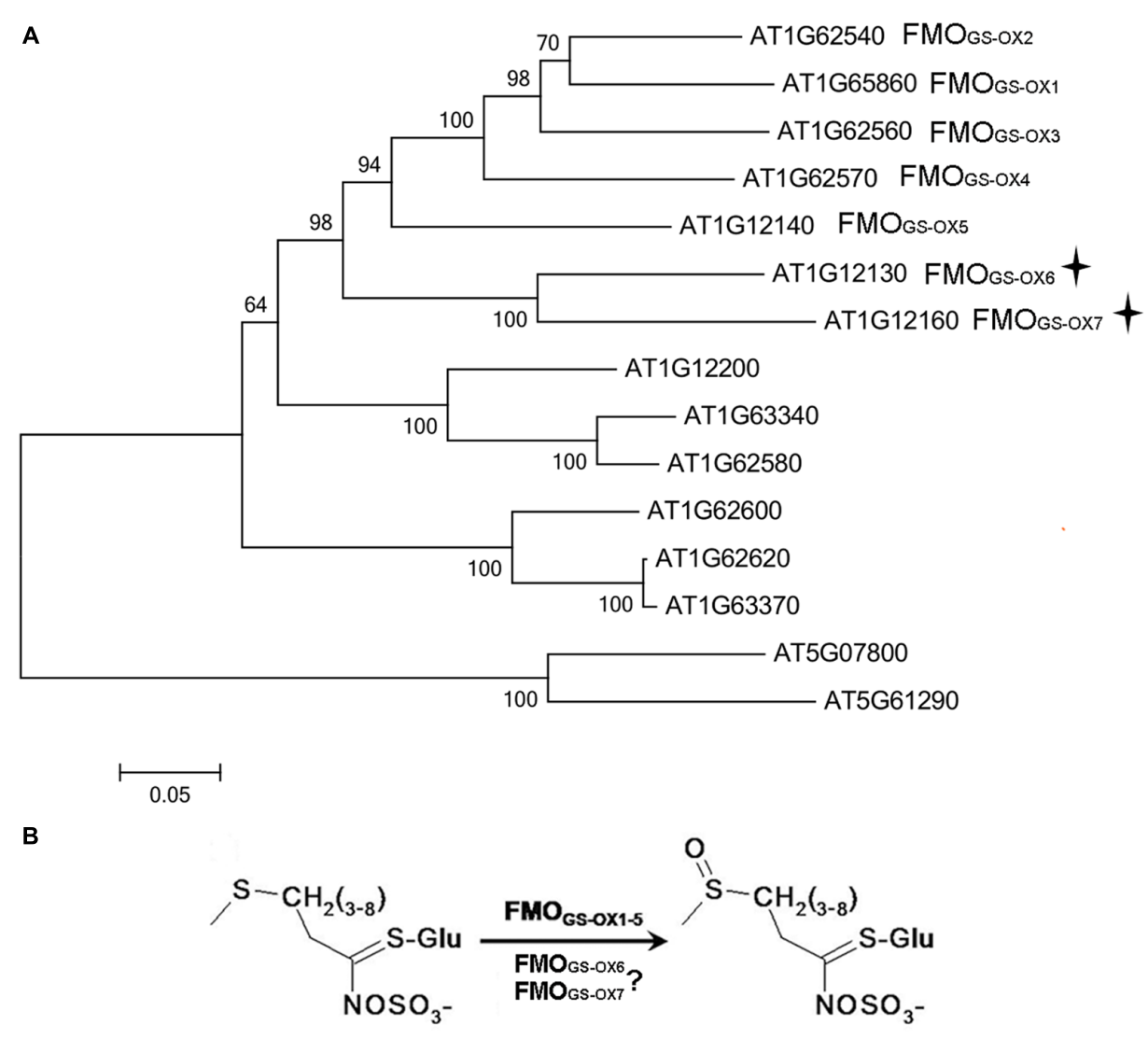

FIGURE 1 | (A) Phylogenetic tree of Arabidopsis flavin-containing monooxygenases (FMOs) possessing the conserved GS-OX domains. (B) FMO GS-ox6 and $\mathrm{FMO}_{\mathrm{GS}-\mathrm{OX7}}$ are predicted to catalyze S-oxygenation of methylthioalkyl (MT) Glucosinolates (GSLs) to methylsulfinylalkyl (MS) GSLs.

CAACGAGTCATCCTGA-3', 5' -TTAGGTTTTGAGCATCGGC AAAAG-3'. The PCR products were then cloned into the expression vector pCAMBIA230035Su using the USER Cloning method as described by Nour-Eldin et al. (2006).

To identify the spatial expression pattern of $F M O_{G S-O X 6}$ and

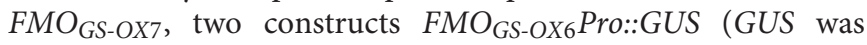
driven by the promoter of $F M O_{G S-O X 6)}$ and $F M O_{G S-O X 7}$ Pro::GUS (GUS was driven by the promoter of $\left.F M O_{G S-O X 7}\right)$, respectively, were prepared. For $F M O_{G S-O X 6}$ Pro::GUS, a 999bp DNA fragment containing the FMOGS-OX6 promoter was amplified with Pfu Turbo Cx Hotstart DNA polymerase (Stratagene) from genomic DNA using the PCR primers $55^{\prime}$-GGCTTAAUGAGTGGTTAATGTGCAACATCA GC-3' and 5'-GGTTTAAUAGTATCAGTCAAAGTATTTGTTT

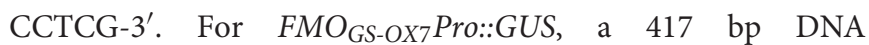
fragment containing the $F_{M O O_{G S-O X 7}}$ promoter was amplified with Pfu Turbo Cx Hotstart DNA polymerase (Stratagene) from genomic DNA using the PCR primers 5'-GGCTTAAUAACGGGATTTTTGATTGGTT-3' ${ }^{\prime}$ and $5^{\prime}$-GGT TTAAUTGTCAAGTCAATTAATGTCAATCTATCAG-3'. The PCR products were then cloned into the expression vector pCAMBIA3300 NLS-GUS by using the USER method as described by Nour-Eldin et al. (2006). pCAMBIA3300 NLS-GUS is generated from the original vector pCAMBIA3300 by adding the NLS (nuclear localization signal) and CDS of the GUS with User cloning sites (Nour-Eldin et al., 2006).

Using Agrobacterium-mediated transformation, all the constructs were transformed into Arabidopsis using the floral-dip method (Clough and Bent, 1998). $T_{0}$ transgenic plants were selected on 1/2 Murashige and Skoog (MS) medium containing $50 \mu \mathrm{g} \cdot \mathrm{mL}^{-1}$ kanamycin. For each construct, three independent confirmed $T_{2}$ transgenic lines were used in the following analysis.

\section{GSL Extraction and Analysis}

35S::FMO ${ }_{G S-O X 6}, \quad 35 S:: F M O_{G S-O X 7}$, wild-type, $F M O_{G S-O X 6}$ knockout mutant, and $F M O_{G S-O X 7}$ knockout mutant plants were grown simultaneously for 24 days. Individual leaves from each plant were harvested for GSL measurement. 50 to $100 \mathrm{mg}$ leaves were used for the extraction. GSL extraction was performed as previously described (Hansen et al., 2007). High performance liquid chromatography (HPLC) analysis was performed by using the method described by Pang et al. (2009).

\section{Spatial Expression Analysis}

The histochemical detection of GUS expression was performed as previously described (Jefferson et al., 1987). Plant materials were cut and incubated in substrate solution at $37^{\circ} \mathrm{C}$ for $12 \mathrm{~h}$ followed by removal of chlorophyll by submerging the samples in $96 \%$ 
ethanol. The samples were examined and photographed using a stereo microscope (Nikon SMZ1270) or a research microscope (Olympus CX21).

For analysis of the responsive expression pattern, seeds of FMO $_{G S-O X 6}$ Pro::GUS, FMO ${ }_{G S-O X 7}$ Pro::GUS, and wild-type plants were vernalized at $4^{\circ} \mathrm{C}$ for $72 \mathrm{~h}$ and allowed to germinate in $1 / 2$ MS medium for 5 days. The plants were then transferred to 1/2 MS medium containing $50 \mu \mathrm{M}$ methyl jasmonate (MeJA), $200 \mu \mathrm{M}$ salicylic acid (SA), and $10 \mu \mathrm{M}$ abscisic acid (ABA), respectively, and were treated for $48 \mathrm{~h}$. The whole seedling was used for GUS detection using the abovementioned method.

\section{Responsive Gene Expression Analysis}

Wild-type seeds were vernalized at $4^{\circ} \mathrm{C}$ for $72 \mathrm{~h}$ and allowed to germinate in $1 / 2 \mathrm{MS}$ medium for 5 days. The seedlings were then transferred to $1 / 2 \mathrm{MS}$ medium containing $100 \mu \mathrm{M}$ indole acetic acid (IAA), $200 \mu \mathrm{M}$ SA, $50 \mu \mathrm{M}$ MeJA, $20 \mathrm{mM} 1-$ aminocyclopropane-1-carboxylic acid (ACC), and $10 \mu \mathrm{M} \mathrm{ABA}$, respectively. For the cold stress and heat stress treatments, seedlings were transferred to 4 and $30^{\circ} \mathrm{C}$ growing chamber, respectively. All the treatments were performed for $24 \mathrm{~h}$.

Total RNA of the treated and control plants were isolated using TRIzol reagent (Invitrogen) and first-strand cDNA was synthesized using the SupermoIII RT kit (Bioteke). The primer pairs used in qRT-PCR for the detection of genes are listed in Supplementary Table S1. qRT-PCR was performed using SYBR Green Master Mix on an ABI 7500 sequence detection system. Relative transcript levels were normalized using ACTIN II as a control.

\section{RESULTS}

\section{Phylogenetic Analysis of $\mathrm{FMO}_{G S-O X}$ Genes in Arabidopsis}

Flavin-containing monooxygenases protein sequences containing the conserved $\mathrm{FMO}_{\mathrm{GS}-\mathrm{OX}}$ domains were obtained from TAIR ${ }^{1}$ and were aligned using ClustalX. It was found that Atlg12130 and Atlg12160 were located in the same subclade, and together with the annotated $\mathrm{FMO}_{\mathrm{GS}-\mathrm{OX1}-5}$ formed a sevenprotein group (Figure 1A), while At1g12200 was located in a subclade adjacent to the seven-protein group (Figure 1A).

Because both the overexpressor and knockout mutant of At1g12200 did not show the expected phenotype (Supplementary Tables S2 and S3), the possibility of At1g12200 to be $\mathrm{FMO}_{\mathrm{GS}-\mathrm{OX}}$ could be excluded. Thus, in the following study, we focused on At1g12130 (named FMO GS-OX6) and At1g12160 (named $\mathrm{FMO}_{\mathrm{GS}-\mathrm{OX7}}$ ) (Figure 1B).

\section{Overexpression of $F M O_{G S-O X 6}$ and FMO $_{\text {GS-OX7 }}$ Altered MT GSLs and MS GSLs Profile}

To confirm whether FMO $_{\mathrm{GS}-\mathrm{OX} 6}$ and $\mathrm{FMO}_{\mathrm{GS}-\mathrm{OX} 7}$ possess S-oxygenation activity, transgenic plants $35 S:: F M O_{G S-O X 6}$ and

${ }^{1}$ https://www.arabidopsis.org/
35S::FMO $\mathrm{GS}_{\mathrm{GX} 7}$ were generated and three independent lines of each FMO $\mathrm{FS}_{\text {-OX6 }}$ and FMO $\mathrm{FS}_{\text {-OX7 }}$ overexpressors were, respectively, used to analysis GSLs profile. Data of the line with the most significant phenotype was shown in Tables $\mathbf{1}$ and 2 . These transgenic plants were confirmed to have much higher expression level than that in wild-type plants by RT-PCR analysis (Supplementary Figure S1). For each plant, the content of GSLs was detected in leaves and seeds of segregating progeny obtained from a heterozygous transgenic parent, thus the possible maternal effects could be minimized. Since the conversion of MT GSLs to MS GSLs rather than the absolute content of MS GSLs could better represent the $S$-oxygenation activity, MT: (MT+MS) was calculated from the HPLC data. Aliphatic GSLs with side chains of different lengths, including C3 (propyl), C4 (butyl), C5 (pentyl), C6 (hexyl), C7 (heptyl), and C8 (octyl), in the leaf and seed tissues of $35 S:: F M O_{G S-O X 6}, 35 S:: F M O_{G S-O X 7}$, and wildtype are shown in Tables 1 and 2. In the seed, MT:(MT+MS) of all the detectable GSLs except propyl, were significantly lower

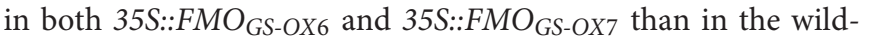
type. In the leaf, MT:(MT+MS) was lower in $35 S:: F M O_{G S-O X 7}$ than in the wild-type, while it was not significantly changed

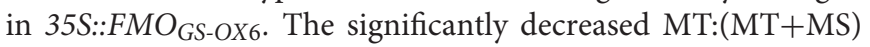
in the seed tissue of the two overexpressors suggested that the FMO $_{\mathrm{GS}-\mathrm{OX} 6}$ and $\mathrm{FMO}_{\mathrm{GS}-\mathrm{OX} 7}$ possess $S$-oxygenation activity for both short-chain and long-chain GSLs. The weak phenotype of overexpressors in the leaf tissue had been previously observed for other $\mathrm{FMO}_{\mathrm{GS}-\mathrm{OX}}$ enzymes (Hansen et al., 2007; Li et al., 2008); this is possibly because of the low content of the substrate (MT GSLs) and the high content of the product (MS GSL) in the leaf, which showed impaired MT converting reaction.

T-DNA knockout mutants $F M O_{G S-O X 6}$ and $F M O_{G S-O X 7}$ were, respectively, analyzed but no significant changes in the GSL profiles were detected (Supplementary Tables S4 and S5). Considering that there are five other identified FMO $_{\mathrm{GS}-\mathrm{OX}}$ enzymes with the same catalytic activity (Hansen et al., 2007; Li et al., 2008), the absence of observable phenotypic effects in the T-DNA knockout mutants could be attributable to the redundancy in gene function.

\section{Expression Pattern of $F M O_{G S-0 x 6}$ and $F M O_{\text {GS-OX7 }}$}

To investigate the spatial expression patterns of $F M O_{G S-O X 6}$ and $F M O_{G S-O X 7}$, we generated the transgenic plants FMO $_{G S-O X 6}$ Pro::GUS and $\mathrm{FMO}_{G S-O X 7}$ Pro::GUS, respectively, expressing the GUS under the control of FMOGS-OX6 and $F M O_{G S-O X 7}$ promoters. Promoter activities were detected by GUS staining, a histochemical technique. As shown in Figure 2, the two genes presented similar expression patterns. In seedlings, the GUS signal was detected in the vascular tissue throughout the radicle, hypocotyls, cotyledon, foliage leaf, and root in both FMO $_{G S-O X 6}$ Pro::GUS and FMO GS-OX7 Pro::GUS transgenic plants (Figures 2A-D, A'-D'). This expression pattern partially overlaps with that of other FMOGS-OX (Li et al., 2011). Similarly, FMO $\mathrm{FS}_{\mathrm{O}-\mathrm{OX} 5}, \quad F M O_{G S-O X 6}$, and $F M O_{G S-O X 7}$ were expressed in the vascular tissue of the foliage, including the midvein and almost all side-veins, while the other four FMOGS-OX 
TABLE 1 | Glucosinolates profile in 35S::FMO ${ }_{\text {GS-OX6 }}$.

\begin{tabular}{|c|c|c|c|c|c|c|}
\hline \multirow[t]{2}{*}{ MT:(MS+MT) } & \multicolumn{3}{|c|}{ Leaf tissue } & \multicolumn{3}{|c|}{ Seed tissue } \\
\hline & WT & 35S:: $F M O_{G S-O X 6}$ & $P$-value & WT & 35S:: $F M O_{G S-O X 6}$ & $P$-value \\
\hline Propyl GSL (C3) & $0.11 \pm 0.009$ & $0.10 \pm 0.005$ & NS & $0.02 \pm 0.001$ & $0.01 \pm 0.000$ & NS \\
\hline Butyl GSL (C4) & $0.28 \pm 0.021$ & $0.27 \pm 0.022$ & NS & $0.90 \pm 0.010$ & $0.57 \pm 0.021$ & $<0.05$ \\
\hline Pentyl GSL (C5) & $0.33 \pm 0.013$ & $0.31 \pm 0.011$ & NS & $0.75 \pm 0.039$ & $0.41 \pm 0.024$ & $<0.05$ \\
\hline Hexyl GSL (C6) & ND & ND & & ND & ND & \\
\hline Heptyl GSL (C7) & $0.30 \pm 0.012$ & $0.31 \pm 0.012$ & NS & $0.77 \pm 0.025$ & $0.40 \pm 0.019$ & $<0.05$ \\
\hline Octyl GSL (C8) & $0.17 \pm 0.011$ & $0.17 \pm 0.012$ & NS & $0.31 \pm 0.013$ & $0.14 \pm 0.011$ & $<0.05$ \\
\hline
\end{tabular}

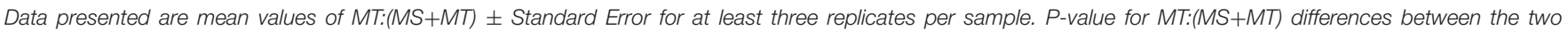

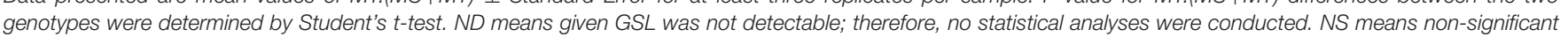
P-value $(P>0.05)$.

TABLE 2 | Glucosinolates profile in 35S::FMO ${ }_{\text {GS-OX7. }}$

\begin{tabular}{|c|c|c|c|c|c|c|}
\hline \multirow[t]{2}{*}{ MT:(MS+MT) } & \multicolumn{3}{|c|}{ Leaf tissue } & \multicolumn{3}{|c|}{ Seed tissue } \\
\hline & WT & 35S:: $F M O_{G S-O X 7}$ & $P$-value & WT & 35S:: $F M O_{G S-O X 7}$ & $P$-value \\
\hline Propyl GSL (C3) & $0.09 \pm 0.004$ & $0.06 \pm 0.003$ & $<0.05$ & $0.03 \pm 0.007$ & $0.04 \pm 0.010$ & NS \\
\hline Butyl GSL (C4) & $0.39 \pm 0.014$ & $0.11 \pm 0.003$ & $<0.05$ & $0.83 \pm 0.024$ & $0.59 \pm 0.011$ & $<0.05$ \\
\hline Pentyl GSL (C5) & $0.43 \pm 0.009$ & $0.30 \pm 0.010$ & $<0.05$ & $0.74 \pm 0.021$ & $0.38 \pm 0.012$ & $<0.05$ \\
\hline Hexyl GSL (C6) & ND & ND & & ND & ND & \\
\hline Heptyl GSL (C7) & $0.35 \pm 0.011$ & $0.20 \pm 0.009$ & $<0.05$ & $0.66 \pm 0.012$ & $0.31 \pm 0.012$ & $<0.05$ \\
\hline Octyl GSL (C8) & $0.13 \pm 0.008$ & $0.06 \pm 0.005$ & $<0.05$ & $0.32 \pm 0.014$ & $0.13 \pm 0.008$ & $<0.05$ \\
\hline
\end{tabular}

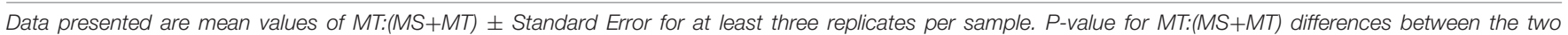

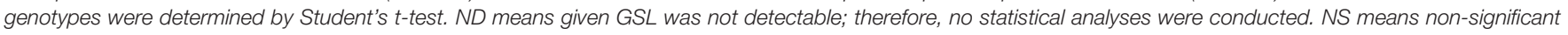
$P$-value $(P>0.05)$.
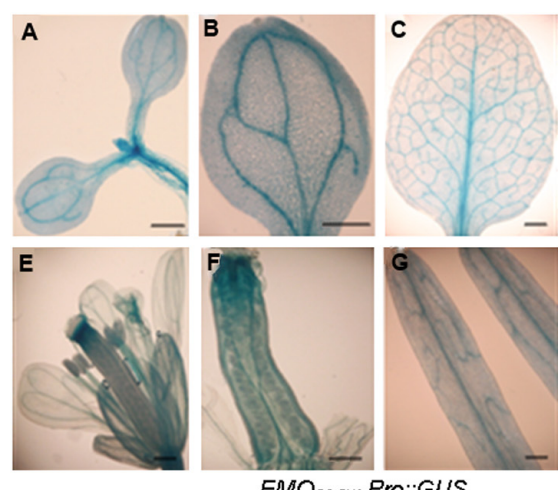

FMOGs-ox6 Pro::GUS
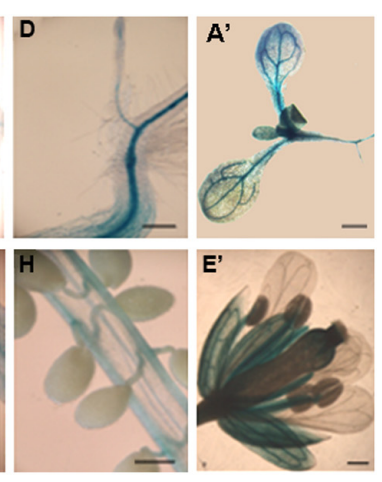
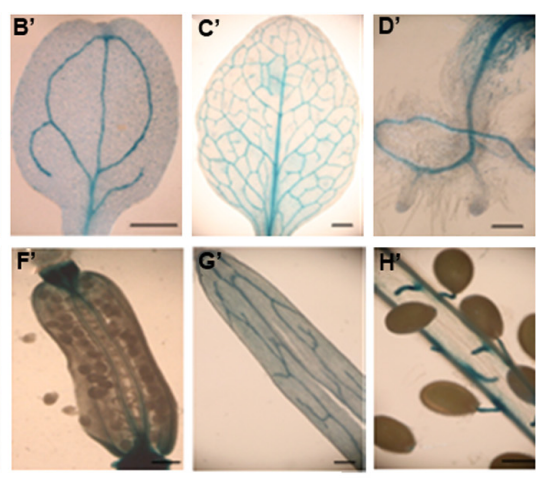

FMOGS-Ox> Pro::GUS
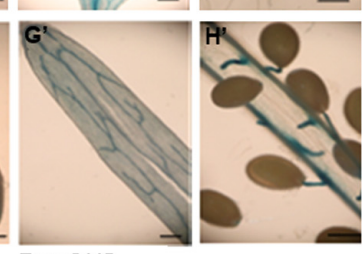

FIGURE 2 | Expression patterns of $\boldsymbol{F M O}_{\mathrm{GS}-\mathrm{OX6}}$ and $\boldsymbol{F M O}_{\mathrm{GS}-\mathrm{Ox} 7}$ detected by promoter-driven $\mathbf{G U S}$ expression. (A,B,A',B') Cotyledons; (C,C') foliage leaf; (D,D') root and hypocotyl; (E,E') flower; (F,F') pistil; (G,G') silique wall; (H,H') Pseudoseptum and seeds; Bar = 0.3 mm.

genes were expressed either only in the mid-vein and some major big veins or only in the side-veins (Li et al., 2011). Both the genes were expressed in the vascular tissue throughout the whole root (Figures 2D,D'), which is again similar to the expression pattern of $F M O_{G S-O X 5}$ and different from that of the other FMO $O_{G S-O X}$ genes, which are expressed only in the connections of the taproot and lateral roots (Li et al., 2011).

For both FMO $_{G S-O X}{ }_{6}$ Pro::GUS and FMO $_{G S-O X 7}$ Pro::GUS, in flowers, GUS signals were detected in the vascular bundles of calyces, carpels, and stamen filaments, but very little signal was detected in petals (Figures 2E-G,E'-G'). Dense GUS signal was clearly observed at the top and bottom of the ovary and seed funicles (Figures 2F,H,F', $\mathbf{H}^{\prime}$ ). This expression pattern is quite similar to that of other $F M O_{G S-O X}$ genes (Li et al., 2011). In general, the spatial expression of FMO ${ }_{G S-O X 6}$ and $F M O_{G S-O X 7}$ overlapped with each other to a large extent and showed a similar pattern in the vascular tissue to that of other GSL biosynthetic genes (Mikkelsen et al., 2000; Reintanz et al., 2001; Tantikanjana et al., 2001; Grubb et al., 2004; Levy et al., 2005; Skirycz et al., 2006; Li et al., 2011). 

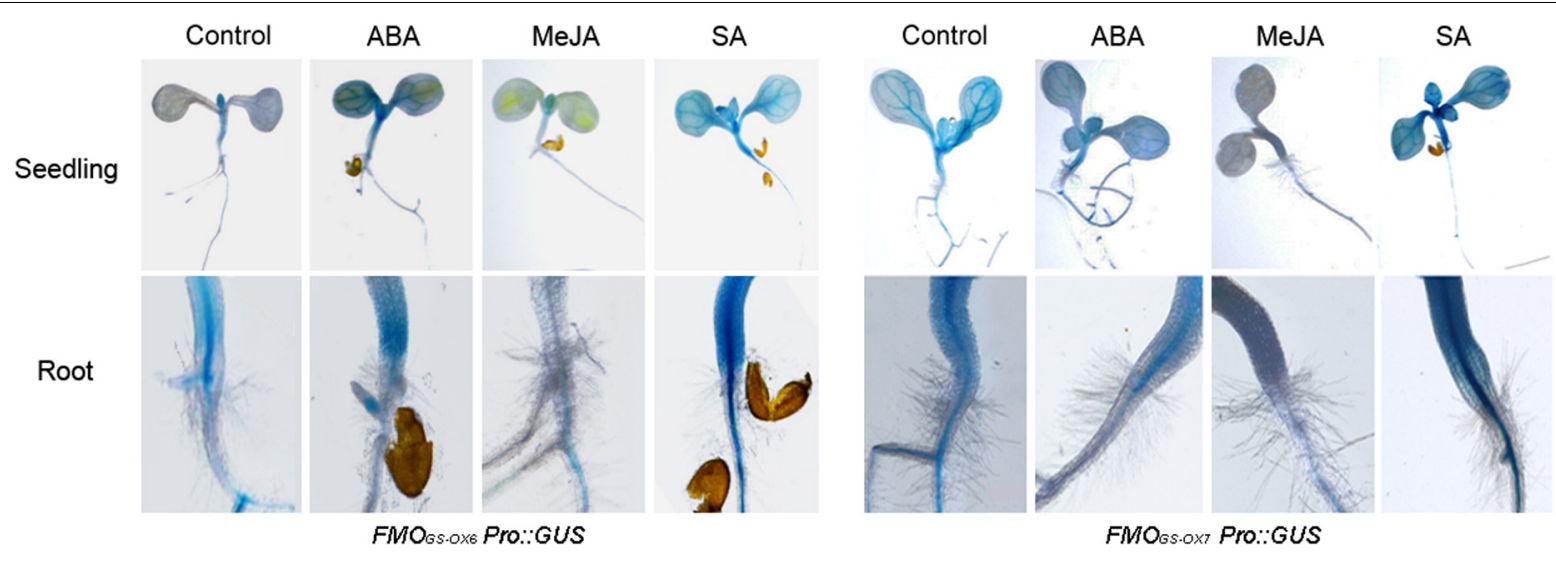

FIGURE 3 | Expression of $F M O_{G S-O x 6}$ and $F M O_{G S-O X 7}$ in response to exogenous abscisic acid (ABA), methyl jasmonate (MeJA), and salicylic acid (SA).

We further detected the expression of the two genes in response to exogenous $\mathrm{ABA}, \mathrm{MeJA}$, and SA. Both FMO $\mathrm{FS}_{\text {-OX6 }}$ and $F_{M O}-O X 7$ were strongly inhibited by MeJA and induced by $\mathrm{SA}$, whereas ABA promoted the expression of FMOGS-OX6 significantly but did not affect $F M O_{G S-O X 7}$ considerably (Figure 3).

\section{Responsive Expression of $F M O_{G S-O X}$ Genes to Different Stimuli}

The S-oxygenation of MT GSLs to MS GSLs is highly important for plant defense because of the bioactivities of MS GSLs against both biotic and abiotic stresses (Stotz et al., 2011; Martínez-Ballesta et al., 2013, 2015). To date, including $\mathrm{FMO}_{\mathrm{GS}-\mathrm{OX} 6}$ and $\mathrm{FMO}_{\mathrm{GS}-\mathrm{OX} 7}$, seven $\mathrm{FMO}_{\mathrm{GS}-\mathrm{OX}}$ enzymes with redundant functions and overlapping spatial distribution have been identified. Therefore, we investigated whether the response of these seven FMO ${ }_{G S-O X}$ genes to environmental stimuli was co-ordinated or varied. The promoter sequences of the seven $F M O_{G S-O X}$ genes were obtained from $\mathrm{NCBI}^{2}$ and analyzed using the web tool Plantcare ${ }^{3}$. The elements in each of the promoter are listed in Supplementary Table S6.

Some common elements were found frequently among these promoters and the function of these elements is responsiveness to $\mathrm{MeJA}, \mathrm{ABA}$, auxin, ethylene, SA, cold, and heat stresses. To investigate the responsive expression of $F M O_{G S-O X}$ and other aliphatic GSL biosynthetic genes toward these hormone and environmental signals, 5-day old seedlings were treated with ABA, ACC, MeJA, SA, IAA, low temperature $\left(4^{\circ} \mathrm{C}\right)$, and high temperature $\left(30^{\circ} \mathrm{C}\right)$. Further, the expression level of the seven $F M O_{G S-O X}$ genes, together with that of $M Y B 28$ (encodes the main transcription factor that regulates aliphatic GSL biosynthetic genes) and CYP83A1 (an aliphatic GSL biosynthetic gene), were determined by qRT-PCR. Except $F M O_{G S-O X 4}$, which maintained relatively stable expression under different conditions, all the genes

${ }^{2}$ http://www.ncbi.nlm.nih.gov/

${ }^{3}$ http://bioinformatics.psb.ugent.be/webtools/plantcare/html/ responded to the treatments (Figure 4). In general, the $F M O_{G S-O X}$ genes showed responsive expression pattern similar to that of the upstream genes (MYB28 and CYP83A1) in the aliphatic GSL biosynthesis pathway. For example, almost all genes were upregulated by ABA and ACC. However, to the same stimulus, different genes presented different level of sensitivity. FMOGS-OX1, FMO $O_{G S-O X 2}, F M O_{G S-O X 6}$, and MYB28 showed upregulation (fivefolds), i.e., high sensitivity,

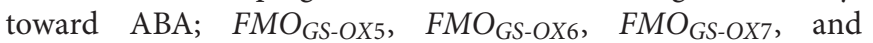
$M Y B 28$, toward ACC; $F M O_{G S-O X 1}$ and MYB28, toward MeJA; $F M O_{G S-O X 7}$ and $M Y B 28$, toward SA; and FMOGS-OX2, $F_{M O} O_{G S-O X 5}$, and $M Y B 28$, toward IAA. None of the aliphatic biosynthetic genes were very sensitive to cold and heat stresses.

\section{DISCUSSION}

Aliphatic GSLs display high structural diversity due to variation in chain length and secondary modification, and the bioactivity of these compounds is largely dependent on the structure of the side chain. The chemical modification catalyzed by the different FMO $_{\mathrm{GS}-\mathrm{OX}}$ enzymes is highly important because MT GSLs and MS GSLs account for a large proportion of total GSLs, and production of MS GSLs is the basis of further modification of aliphatic GSLs.

The five annotated $\mathrm{FMO}_{\mathrm{GS}-\mathrm{Ox}}$ enzymes were identified by Hansen (Hansen et al., 2007) and Li (Li et al., 2008). In the study conducted by Hansen, a phylogenetic tree of plant FMOs from rice, Arabidopsis, and poplar was analyzed. Within the clade considered to be involved in S-oxygenation, the presence of a subclade of seven proteins, including the annotated $\mathrm{FMO}_{\mathrm{GS}-\mathrm{OX1} 1-5}, \mathrm{FMO}_{\mathrm{GS}-\mathrm{OX} 6}$, and $\mathrm{FMO}_{\mathrm{GS}-\mathrm{OX} 7}$, only in the GSL-producing Arabidopsis plant suggests that these genes may be responsible for S-oxygenation of GSLs. Our result verified Hansen's prediction. Compared with the known $\mathrm{FMO}_{\mathrm{GS}-\mathrm{OX}}$ enzymes, $\mathrm{FMO}_{\mathrm{GS}-\mathrm{OX} 6}$ and $\mathrm{FMO}_{\mathrm{GS}-\mathrm{OX} 7}$ was quite similar to $\mathrm{FMO}_{\mathrm{GS}-\mathrm{OX1}-4}$, which contribute to the conversion 

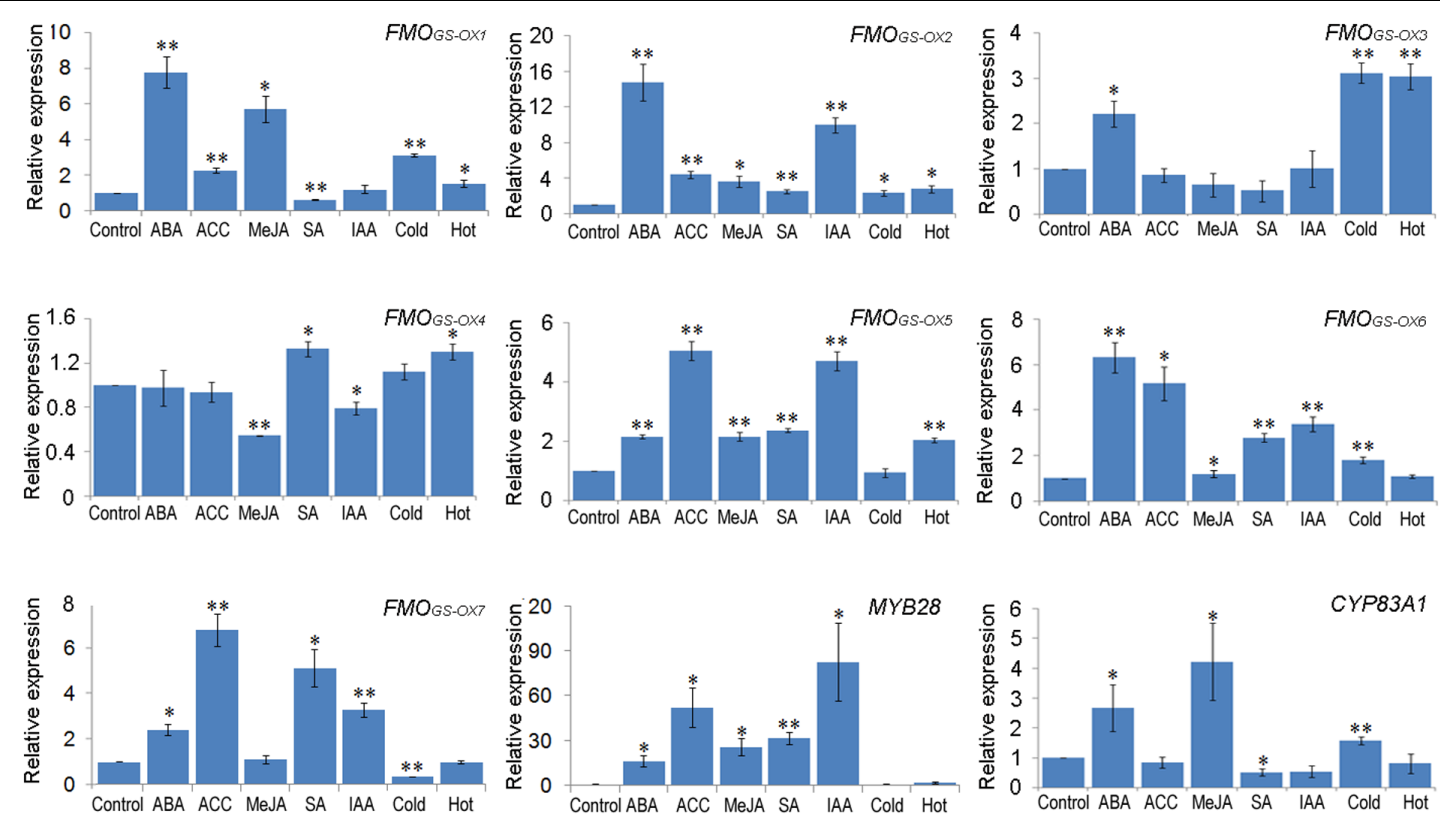

FIGURE 4 | Responsive expression patterns of $\boldsymbol{F M O}_{\text {GS-ox }}$ genes to different exogenous stimuli. The mRNA abundance of nine genes was analyzed by qRT-PCR. Samples for qRT-PCR were run in three biological replicates with three technical replicates and the data were represented as the Mean \pm SD $(n=3)$. The relative gene expression was calculated using the $\Delta \Delta \mathrm{Ct}$ algorithm. The expression data were normalized using the invariant expression of $A C T I N$ II. The leaves from mock control seedlings were used as reference sample, which was set to 1 . Significant differences according to Student's $t$-test are indicated: ${ }^{*} P<0.05$,

$* * P<0.01$

of both short and long-chain MT GSLs, and was different from $\mathrm{FMO}_{\mathrm{GS}-\mathrm{OX} 5}$, which specifically recognizes long-chain substrates.

$F_{M O} O_{G-O X 6}$ and $F_{M O} O_{G S-O X 7}$ showed very similar spatial expression patterns and it overlapped with that of most other GSL biosynthetic genes, which are frequently found in the vascular bundle. However, some small variations can be observed between these FMO ${ }_{G S-O X}$ genes. Li et al. (2011) reported that in the leaf, $F M O_{G S-O X 1-4}$ were distributed partially in the veins and FMO GS-OX5 was expressed in the mid-vein and all the branched veins, whereas in the root, $F M O_{G S-O X 1-4}$ was limited to the connections between the taproot and lateral roots and $\mathrm{FMO}_{G S-O X 5}$ was present throughout the vascular tissue in the whole root. Interestingly, $\mathrm{FMO}_{\mathrm{GS}-\mathrm{OX} 6}$ and $\mathrm{FMO}_{\mathrm{GS}-\mathrm{OX} 7}$, like $\mathrm{FMO}_{\mathrm{GS}-\mathrm{OX} 1-4}$, catalyze $S$-oxygenation of GSLs without substrate specificity and exhibit less specific spatial expression like $\mathrm{FMO}_{\mathrm{GS}-\mathrm{OX} 5}$. Based on the phylogenetic analysis of the $F M O_{G S-O X}$ genes in Arabidopsis (Figure 1A), our results suggest an $\mathrm{FMO}_{\mathrm{GS}-\mathrm{OX}}$ ancestor with a broad range of non-specific substrates for catalysis and broad spatial expression. The gene encoding this ancestor could probably have been duplicated into two groups: one (comprising $F_{M O} O_{G S-O X 1-5}$ ) might have become more specific either in spatial expression $\left(F M O_{G S-O X 1-4}\right)$ or in substrate recognition $\left(F M O_{G S-O X 5}\right)$ and the other group (comprising $F_{M O} O_{G S-O X 6}$ and $F_{\left.M O O_{G S-O X 7}\right)}$ remained non-specific in both aspects.

Some common elements were detected in the promoter sequences of these FMO $\mathrm{FS}_{\mathrm{G}-\mathrm{OX}}$ genes.
Consistently, the $F M O_{G S-O X}$ genes presented similar responsive expression tendency under several hormone treatments and temperature stresses. However, the sensitivity of each gene differed in response to the same treatment.

Integrating the knowledge of the various $F M O_{G S-O X}$ genes, we observed that they are quite redundant in their catalytic activity, distribution pattern, and response to exogenous stimuli. It is considered that duplicate genes play a more important role for the compensation of secondary metabolites than that of primary metabolites because there are fewer alternative pathways in secondary metabolite synthesis (Hanada et al., 2011). This redundancy of $F M O_{G S-O X}$ genes might play a significant role in functional compensation and increasing genetic robustness. Additionally, the variations found among these $F M O_{G S-O X}$ genes could possibly result in delicate functional difference and contribute to the finely tuned modification of aliphatic GSLs.

Aliphatic GSLs are primarily considered to contribute to plant resistance toward pests (Beekwilder et al., 2008). Recent studies discovered multiple functions of these compounds; they are involved in toxicity against pathogens and have been suggested to contribute to maintaining water balance under salt stress (Tierens et al., 2001; Stotz et al., 2011; Martínez-Ballesta et al., 2015). The versatile bioactivity of aliphatic GSLs is largely dependent on the length and modification of their side chain (Stotz et al., 2011). However, the contribution of specific metabolites to the biotic or abiotic stress defenses is still poorly understood. Identification of 
new FMO $_{\mathrm{GS}-\mathrm{OX}}$ enzymes provides a way to investigate the specific bioactivity of aliphatic GSLs with different side chain structures. As an application for humans, these $F M O_{G S-O X}$ genes can potentially be used in breeding Brassica vegetables with improved anti-cancer properties conferred by the MS GSLs.

\section{AUTHOR CONTRIBUTIONS}

JL and WK carried out experiments and analyzed experiment results. QY, WC, and RX carried out partial of the experiments. $\mathrm{JL}$ and WK wrote the manuscript. WJ designed the experiments.

\section{REFERENCES}

Atwell, L. L., Beaver, L. M., Shannon, J., Williams, D. E., Dashwood, R. H., and Ho, E. (2015). Epigenetic regulation by sulforaphane: opportunities for breast and prostate cancer chemoprevention. Curr. Pharmacol. Rep. 2, 102-111. doi: 10.1007/s40495-014-0002-x

Bednarek, P., Pislewska-Bednarek, M., Svatos, A., Schneider, B., Doubsky, J., Mansurova, M., et al. (2009). A glucosinolate metabolism pathway in living plant cells mediates broad-spectrum antifungal defense. Science 323, 101-106. doi: 10.1126/science.1163732

Beekwilder, J., Leeuwen, W. V., Dam, N. M. V., Bertossi, M., Grandi, V., Mizzi, L., et al. (2008). The impact of the absence of aliphatic glucosinolates on insect herbivory in Arabidopsis. PLoS ONE 3:e2068. doi: 10.1371/journal.pone.0002068

Bones, A. M., and Rossiter, J. T. (2006). The enzymic and chemically induced decomposition of glucosinolates. Phytochemistry 67, 1053-1067. doi: 10.1016/.jphytochem.2006.02.024

Chang, Y. W., Jang, J. Y., Kim, Y. H., Kim, J. W., and Shim, J. J. (2015). The effects of broccoli sprout extract containing sulforaphane on lipid peroxidation and Helicobacter pyloriinfection in the gastric mucosa. Gut Liver. 9, 486-493. doi: $10.5009 /$ gnl 14040

Clay, N. K., Adio, A. M., Denoux, C., Jander, G., and Ausubel, F. M. (2009). Glucosinolate metabolites required for an Arabidopsis innate immune response. Science 323, 95-101. doi: 10.1126/science.1164627

Clough, S. J., and Bent, A. F. (1998). Floral dip: a simplified method for Agrobacterium-mediated transformation of Arabidopsis thaliana. Plant J. 16, 735-743. doi: 10.1046/j.1365-313x.1998.00343.x

Fahey, J. W., Haristoy, X., Dolan, P. M., Kensler, T. W., Scholtus, I., Stephenson, K. K., et al. (2002). Sulforaphane inhibits extracellular, intracellular, and antibiotic-resistant strains of Helicobacter pylori and prevents benzo[ $\alpha]$ pyreneinduced stomach tumors. Proc. Natl. Acad. Sci. U.S.A. 99, 7610-7615. doi: 10.1073 pnas.112203099

Fahey, J. W., Zhang, Y., and Talalay, P. (1997). Broccoli sprouts: an exceptionally rich source of inducers of enzymes that protect against?chemical?carcinogens. Proc. Natl. Acad. Sci. U.S.A. 94, 10367-10372. doi: 10.1073/pnas.94.19. 10367

Fofaria, N. M., Ranjan, A., Kim, S. H., and Srivastava, S. K. (2015). Mechanisms of the anticancer effects of isothiocyanates. Enzymes 37, 111-137. doi: 10.1016/bs.enz.2015.06.001

Grubb, C. D., Zipp, B. J., Ludwig-Muller, J., Masuno, M. N., Molinski, T. F., and Abel, S. (2004). Arabidopsis glucosyltransferase UGT74B1 functions in glucosinolate biosynthesis and auxin homeostasis. Plant J. 40, 893-908. doi: 10.1111/j.1365-313X.2004.02261.x

Halkier, B. A., and Gershenzon, J. (2006). Biology and biochemistry of glucosinolates. Annu. Rev. Plant Biol. 57, 303-333. doi: 10.1146/annurev.arplant.57.032905.105228

Hanada, K., Sawada, Y., Kuromori, T., Klausnitzer, R., Saito, K., Toyoda, T., et al. (2011). Functional compensation of primary and secondary metabolites

\section{ACKNOWLEDGMENTS}

This work was supported by National Natural Science Foundation of China (NSFC) 31370334, NSFC 31170368, and Science and Technology Research Project of Education Department of Heilongjiang Province, 2531003.

\section{SUPPLEMENTARY MATERIAL}

The Supplementary Material for this article can be found online at: http://journal.frontiersin.org/article/10.3389/fpls.2016.01292

FIGURE S1 | Expression levels of $F M O_{G S-O X 6}$ and $F M O_{G S-O X 7}$ in the overexpression mutants.

by duplicate genes in Arabidopsis thaliana. Mol. Biol. Evol. 1, 377-382. doi: 10.1093/molbev/msq204

Hansen, B. G., Kliebenstein, D. J., and Halkier, B. A. (2007). Identification of a flavinmonooxygenaseas the S-oxygenating enzyme in aliphatic glucosinolate biosynthesis in Arabidopsis. Plant J. 50, 902-910. doi: 10.1111/j.1365313X.2007.03101.x

Hopkins, R. J., Dam, N. M. V., and Loon, J. J. A. V. (2009). Role of glucosinolates in insect-plant relationships and multitrophic interaction. Annu. Rev. Entomol. 54, 57-83. doi: 10.1146/annurev.ento.54.110807.090623

Jefferson, R., Kavanagh, T. A., and Bevan, M. W. (1987). GUS fusions: Bglucuronidase as a sensitive and versatile gene fusion marker inhigher plants. EMBO J. 16, 3901-3907.

Laluk, K., Prasad, K. V., Savchenko, T., Celesnik, H., Dehesh, K., Levy, M., et al. (2012). The calmodulin-binding transcription factor SIGNAL RESPONSIVE1 is a novel regulator of glucosinolate metabolism and herbivory tolerance in Arabidopsis. Plant Cell Physiol. 53, 2008-2015. doi: 10.1093/pcp/pcs143

Levy, M., Wang, Q., Kaspi, R., Parrella, M. P., and Abel, S. (2005). Arabidopsis IQD1, a novel calmodulin-binding nuclear protein, stimulates glucosinolate accumulation and plant defense. Plant J. 43, 79-96. doi: 10.1111/j.1365313X.2005.02435.x

Li, J., Hansen, B. G., Ober, J. A., Kliebenstein, D. J., and Halkier, B. A. (2008). Subclade of flavinmonooxygenasesinvolved in aliphatic glucosinolate biosynthesis. Plant Physiol. 148, 1721-1733. doi: 10.1104/pp.108.125757

Li, J., Kristiansen, K. A., Hansen, B. G., and Halkier, B. A. (2011). Cellular andsubcellular localization of flavin-monooxygenases involved in glucosinolatebiosynthesis. J. Exp. Bot. 62, 1337-1346. doi: 10.1093/jxb/ erq369

Marchler-Bauer, A., Derbyshire, M. K., Gonzales, N. R., Lu, S., Chitsaz, F., Geer, L. Y., et al. (2015). CDD: NCBI's conserved domain database. Nucleic Acids Res. 43, 222-226. doi: 10.1093/nar/gku1221

Martínez-Ballesta, M. C., Moreno-Fernández, D. A., and Carvajal, M. (2013). The Physiological importance of glucosinolates on plant response to abiotic stress in Brassica. Int. J. Mol. Sci. 14, 11607-11625. doi: 10.3390/ijms14061 1607

Martínez-Ballesta, M. C., Moreno-Fernández, D. A., Castejón, D., Ochando, C., Morandini, P. A., and Carvajal, M. (2015). The impact of the absence of aliphatic glucosinolates on water transport under salt stress in Arabidopsis thaliana. Front. Plant Sci. 6:524. doi: 10.3389/fpls.2015. 00524

Mikkelsen, M. D., Hansen, C. H., Wittstock, U., and Halkier, B. A. (2000). Cytochrome P450 CYP79B2 from Arabidopsis catalyzes the conversion of tryptophan to indole-3-acetaldoxime, a precursor of indole glucosinolates and indole-3-acetic acid. J. Biol. Chem. 275, 33712-33717. doi: 10.1074/jbc.M001667200

Nour-Eldin, H. H., Hansen, B. G., Nørholm, M. H., Jensen, J. K., and Halkier, B. A. (2006). Advancing uracil-excision based cloning towards an ideal techniquefor cloning PCR fragments. Nucleic Acids Res. 34:e122. doi: 10.1093/nar/ gkl635 
Pang, Q., Chen, S., Li, L., and Yan, X. (2009). Characterizationof glucosinolate-myrosinase system in developing salt cress Thellungiella halophila. Physiol. Plant 136, 1-9. doi: 10.1111/j.1399-3054.2009. 01211.x

Reintanz, B., Lehnen, M., Reichelt, M., Gershenzon, J., Kowalczyk, M., Sandberg, G., et al. (2001). Bus, a bushy Arabidopsis CYP79F1 knockout mutant with abolished synthesis of short-chain aliphatic glucosinolates. Plant Cell 13, 351-367. doi: 10.2307/3871281

Rose, P., Faulkner, K., Williamson, G., and Mithen, R. (2000). 7Methylsulfinylheptyl and 8-methylsulfinyloctyl isothiocyanates from watercress are potent inducers of phase II enzymes. Carcinogenesis 21, 1983-1988. doi: $10.1093 / \mathrm{carcin} / 21.11 .1983$

Rose, P., Huang, Q., Ong, C. N., and Whiteman, M. (2005). Broccoli and watercress suppress matrix metalloproteinase- 9 activity and invasiveness of human MDAMB-231 breast cancer cells. Toxicol. Appl. Pharmacol. 209, 105-113. doi: 10.1016/j.taap.2005.04.010

Skirycz, A., Reichelt, M., Burow, M., Birkemeyer, C., Rolcik, J., Kopka, J., et al. (2006). DOF transcription factor AtDof1.1 (OBP2) is part of a regulatory network controlling glucosinolate biosynthesis in Arabidopsis. Plant J. 47, 10-24. doi: 10.1111/j.1365-313X.2006. 02767.x

Stotz, H. U., Sawada, Y., Shimada, Y., Hirai, M. Y., Sasaki, E., Krischke, M., et al. (2011). Role of camalexin, indole glucosinolates, and side chain modification of glucosinolate-derived isothiocyanates in defense of Arabidopsis against Sclerotinia sclerotiorum. Plant J. 67, 81-93. doi: 10.1111/j.1365313X.2011.04578.x

Talalay, P., Fahey, J. W., Healy, Z. R., Wehage, S. L., Benedict, A. L., Min, C., et al. (2007). Sulforaphane mobilizes cellular defenses that protect skin against damage by UV radiation. Proc. Natl. Acad. Sci. U.S.A. 104, 17500-17505. doi: 10.1073/pnas.0708710104

Tantikanjana, T., Yong, J. W., Letham, D. S., Griffith, M., Hussain, M., Ljung, K., et al. (2001). Control of axillary bud initiation and shoot architecture in Arabidopsis through the SUPERSHOOT gene. Gene Dev. 15, 1577-1588. doi: $10.1101 /$ gad. 887301

Tierens, K. J., Thomma, B., Brower, M., Schmidt, J., Kistner, K., Porzel, A., et al. (2001). Study of the role of antimicrobial glucosinolate-derived isothiocyanates in resistance of Arabidopsis to microbial pathogens. Plant Physiol. 125, 16881699. doi: $10.1104 /$ pp.125.4.1688

Zalcmann, A. T., and Talalay, P. (2001). The chemical diversity and distribution of glucosinolates and isothiocyanates among plants. Phytochemistry 56, 5-51.

Zhang, Z., Ober, J. A., and Kliebenstein, D. J. (2006). The gene controlling thequantitative trait locus EPITHIOSPECIFIER MODIFIER1 alters glucosinolatehydrolysis and insect resistance in Arabidopsis. Plant Cell 18, 1524-1536. doi: $10.1105 /$ tpc. 105.039602

Conflict of Interest Statement: The authors declare that the research was conducted in the absence of any commercial or financial relationships that could be construed as a potential conflict of interest.

Copyright (c) 2016 Kong, Li, Yu, Cang, Xu, Wang and Ji. This is an open-access article distributed under the terms of the Creative Commons Attribution License (CC BY). The use, distribution or reproduction in other forums is permitted, provided the original author(s) or licensor are credited and that the original publication in this journal is cited, in accordance with accepted academic practice. No use, distribution or reproduction is permitted which does not comply with these terms. 